Check for updates

Cite this: Chem. Commun., 2017, 53, 10192

Received 25th July 2017,

Accepted 22nd August 2017

DOI: $10.1039 / c 7 c c 05770 a$

rsc.li/chemcomm

\section{Halogen free 1,2,3- and 1,2,4-triazolide based ionic liquids: synthesis and properties $\dagger$}

\author{
Aleksandr Savateev, (DD*a Clemens Liedel, (D) ${ }^{\text {a }}$ Steffen Tröger-Müller, ${ }^{a}$ \\ Alberto S. de León, ${ }^{b}$ Markus Antonietti ${ }^{a}$ and Dariya Dontsova (D) ${ }^{a}$
}

Triazoles have been successfully used as building blocks to create "fully organic" ILs featuring on both sides organic ions, i.e., 1,2,3- or 1,2,4-triazolide anions and 1,2,4-triazolium or imidazolium cations. Glass transition temperatures, densities and viscosities of these ILs were determined. Their electrochemical and thermal stability, and also conductivity, are higher than those for known ILs.

Ionic liquids (ILs) are in the focus of modern materials chemistry and, for instance, used as a medium to perform chemical transformation as well as for electrochemical and even biological applications. $^{1-3}$ The vast majority of ILs are represented by an organic cation, typically imidazolium, and an inorganic or halogenated counterion. The pathways of anion decompositions were explored both theoretically and experimentally. ${ }^{4}$ For example, the reduction of the triflimidate anion, $\mathrm{Tf}_{2} \mathrm{~N}^{\ominus}$, starts at $-2.0 \mathrm{~V} v s$. $\mathrm{Fc}^{+} / \mathrm{Fc}$ and includes cleavage of the $\mathrm{S}-\mathrm{N}$ bond followed by the formation of $\mathrm{CF}_{3}{ }^{\ominus}{ }^{5}$ In contrast, $\mathrm{PF}_{6}{ }^{\ominus}$ is slowly oxidized on the anode producing toxic gaseous $\mathrm{PF}_{5}$ and $\mathrm{F}^{\bullet}$ radical, which upon hydrogen abstraction is converted to HF. ${ }^{6}$ On the other hand, B-F bond cleavage in $\mathrm{BF}_{4}{ }^{\ominus}$ occurs upon contact with water even under very mild conditions. ${ }^{7}$ Considering potential risks that fluorinated ILs might carry, a good alternative could be halogen free ILs.

"Fully organic" ILs, having both organic cations and anions, are less common ${ }^{8}$ and usually comprise simple anions like acetate, bringing however obvious restrictions in use. ${ }^{9}$ In this context, 1,2,3- and 1,2,4-triazoles are an interesting choice of heterocycles which form both stable cations and anions. This enables to set up a new class of ILs. The advantage of "fully organic" triazole-based ILs is their chemical stability, but they also possess many nitrogen atoms which can participate in H-bonding with the solute. This makes them potentially

\footnotetext{
${ }^{a}$ Max-Planck Institute of Colloids and Interfaces, Department of Colloid Chemistry, Research Campus Golm, 14424 Potsdam, Germany.

E-mail: oleksandr.savatieiev@mpikg.mpg.de

${ }^{b}$ Max-Planck Institute of Colloids and Interfaces, Mechano(bio)chemistry, Research Campus Golm, 14424 Potsdam, Germany

$\dagger$ Electronic supplementary information (ESI) available: Experimental procedures, NMR and HR-MS spectra, TGA-MS, DSC. See DOI: 10.1039/c7cc05770a
}

more compatible with many organic substances since "similia similibus solvuntur".

Triazolium cations (A, Fig. 1) are stabilized via conjugation with nitrogen lone pairs as well as through the inductive effect of electron-donating functional groups, which additionally may affect the charge distribution within the molecule affording task specific ILs for targeted application. ${ }^{10}$ The advantage of triazolium ILs compared to widely used imidazolium ones is the reduction in number or even suppression of side-reactions caused by deprotonation of the ring carbon atoms of heterocyclic cations. ${ }^{11}$ Some 1,2,3-triazolium ILs were successfully used as a medium for the Baylis-Hillman reaction ${ }^{11}$ and for $( \pm)$-centrolobine synthesis ${ }^{12}$ while bicyclic triazolium ILs were applied as molecular solvents for rutaecarpine synthesis. ${ }^{13}$ Besides, several 1,2,3-triazolium ILs with tosylate and $\mathrm{TfO}^{\ominus}$ anions were synthesized and characterized. ${ }^{14}$

Conversely, in the triazolide anion (B, Fig. 1) three nitrogen atoms can effectively stabilize negative charges and lower the IL viscosity. ${ }^{15}$ In addition, due to the smaller size of the organic anion compared, for example, to $\mathrm{Tf}_{2} \mathrm{~N}^{\ominus}$, the ion mobility of the IL is expected to be higher. As a result of the low acidity of 1,2,4- and 1,2,3-triazoles, their corresponding anions are considered to be superbases, ${ }^{16}$ and several 1,2,3-triazolide ILs were used for $\mathrm{CO}_{2}$ capture ${ }^{17}$ and $\mathrm{CO}_{2}$ electrochemical reduction. ${ }^{18-20}$ The triazole-1,2,4-ide anion was employed as a part of highly energetic ILs as well. ${ }^{21}$ However, their electrochemical properties remain unexplored.

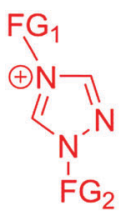

A<smiles>CCCCCCc1noc(C(F)(F)F)n1</smiles>

or<smiles></smiles>

B
Fig. 1 Cationic triazole-1,2,4-based IL (A) and anionic triazole-1,2,4(B, left) or triazole-1,2,3-based ILs (B, right). FG stands for 'functional group'. 
<smiles>Cn1cc[n+](C)c1Cl</smiles><smiles>Cn1nc(C#N)c(C#N)n1</smiles><smiles></smiles><smiles>N#Cc1n[nH]nc1C#N</smiles>

IL-1<smiles></smiles><smiles></smiles><smiles>Nn1cnnc1</smiles><smiles>N#Cc1n[nH]nc1C#N</smiles>

IL-2<smiles>Cn1cc[n+](C)c1Cl</smiles><smiles>Cn1ncnc1[N+](=O)[O-]</smiles>

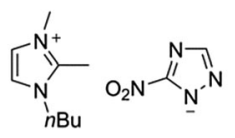

IL-3

Fig. 2 Synthesis of ILs by ion metathesis reactions.

Triazoles could be an excellent platform to synthesize "fully organic" ILs, comprising triazolium cations and triazolide anions. However, throughout the challenging design a number of criteria should be kept in mind. These include the acidity of the target triazole, which functional groups to use to adjust the triazole properties, and the synthetic approach to employ.

Herein we report on the synthesis of a set of "fully organic" triazole based ILs and their properties.

Triazoles, bearing $\mathrm{NO}_{2}$ and $\mathrm{CN}$ functional groups, were selected as anion precursors due to the ability of these groups to stabilize efficiently a negative charge via a $(-\mathrm{M})$ mesomeric effect. IL precursors $2 H$-1,2,3-triazole-4,5-dicarbonitrile, ${ }^{22}$ 3-nitro- $1 H$ 1,2,4-triazole, ${ }^{23}$ 1-methyl-4-amino-4H-1,2,4-triazol-1-ium iodide ${ }^{24}$ 2 were synthesized by us according to the procedures given in the literature.

The ILs studied in the current work were obtained in high yields via ion metathesis reactions as depicted in Fig. 2. The method provides ILs with high purity, as shown below, and without laborious purification procedures. The chemical composition of the ILs is very close to the calculated one (Table S1, ESI $\dagger$ ). IL-1, IL-2 and IL-3 are free of any foreign elements, e.g. $\mathrm{Ag}, \mathrm{Cl}$, and I, which was unambiguously proved by EDX analysis (Fig. S2 and Table S1, ESI $\dagger$ ). ${ }^{25,26}$ The water mass fraction $\left(w_{\mathrm{w}}\right)$ in the ILs after drying under vacuum $\left(0.1 \mathrm{mbar}, 65{ }^{\circ} \mathrm{C}, 4 \mathrm{~h}\right)$ determined using Karl-Fischer titration in IL-1 was $w_{\mathrm{w}}=0.00832 \pm$ $0.0002, \mathrm{IL}-2 w_{\mathrm{w}}=0.0144 \pm 0.0008$ and IL-3 $w_{\mathrm{w}}=0.0102 \pm 0.0004$ (Table S1, ESI $\dagger$ ).

The structures of ILs are consistent with ${ }^{1} \mathrm{H}$ and ${ }^{13} \mathrm{C}$ NMR spectra including two-dimensional techniques (Fig. S3-S23, ESI $\dagger$ ). The full assignment of peaks in the NMR spectra to specific nuclei was performed (Fig. S24, ESI $\dagger$ ). In HR-MS spectra the masses of the cation and anion were observed independently in the positive and negative ion modes proving that all these compounds can give stable charged species (Fig. S25-S27, ESI $\dagger$ ). Combining ${ }^{1} \mathrm{H}$ NMR data with elemental analysis and water content the purity of the ILs (in mass fraction) was determined to be 0.968-0.982 (Table S1, ESI $\dagger$ ).

At room temperature IL-1, IL-2, and IL-3 are viscous liquids. The glass transition temperatures $\left(T_{\mathrm{g}}\right)$ of the ILs were determined from differential scanning calorimetry (DSC) curves (Fig. 3a) and are summarized in Table 1. The ILs are stable in
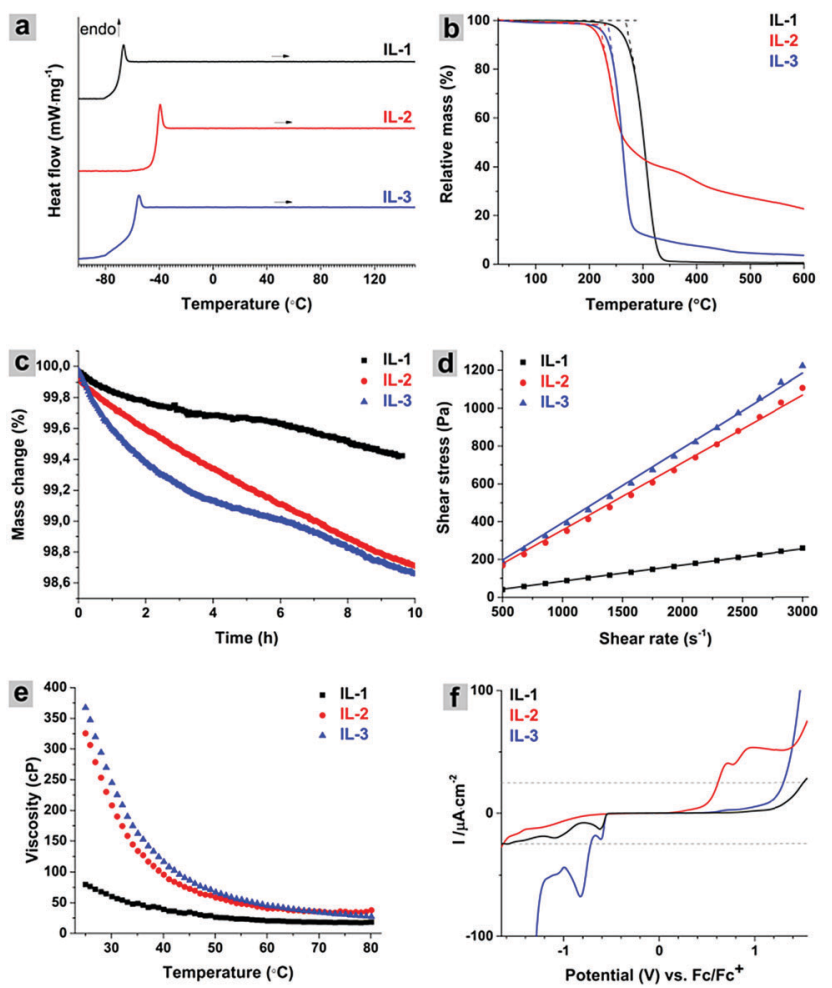

Fig. 3 DSC heating curve in the temperature range of $-100 \ldots+150{ }^{\circ} \mathrm{C}$ performed under a flow of nitrogen. The fourth cycles are plotted (a); ramp TGA, heating rate $2.5 \mathrm{~K} \mathrm{~min}^{-1}$ (b); isothermal TGA performed at $120{ }^{\circ} \mathrm{C}$ (c); shear stress-shear rate dependence measured at $25^{\circ} \mathrm{C}(\mathrm{d})$; dependence of IL dynamic viscosity on temperature (e); LSV curves of ILs (f).

the temperature range of $-100 \ldots+150{ }^{\circ} \mathrm{C}$ as proved by the identity of $T_{\mathrm{g}}$ values during cyclic heating/cooling (Fig. S28, ESI $\dagger$ ). IL-1 has $T_{\mathrm{g}}=-66.6{ }^{\circ} \mathrm{C}$, which is higher than that for 1-butyl-3-methyl-1 $H$-imidazol-3-ium 4,5-dicyano-1,2,3-triazol-2-ide, $-87{ }^{\circ} \mathrm{C}$ (heating rate $2{ }^{\circ} \mathrm{C} \mathrm{min}^{-1}$ ), evidently due to the presence of a methyl group in the second position of the imidazole ring. ${ }^{15}$

Interestingly, due to the compact size of the 1,2,4-triazolium cation, one could expect a high melting point of IL-2. However, this is not the case, as IL-2 still possesses a relatively low $T_{\mathrm{g}}=-39.0{ }^{\circ} \mathrm{C}$, probably due to the influence of the anion. IL-3 demonstrates quite low $T_{\mathrm{g}}=-55.4{ }^{\circ} \mathrm{C}$ that could be explained, at least partially, by the lower symmetry of the anion compared, for example, to 1,2,3-triazolide.

The thermal stability and thermal decomposition pathways of the synthesized ILs were explored using thermogravimetric analysis mass spectroscopy (TGA-MS). The onset of decomposition $\left(T_{\text {dec }}\right)$ values extracted from the TGA curves (Fig. 3b) are summarized in Table $1 . T_{\mathrm{dec}}$ values could be used as a descriptor of IL thermal stability upon short exposure to high temperatures. We have monitored charged species with $\mathrm{m} / \mathrm{z}$ in the range of 1-200 that are formed during the IL heating up to $600{ }^{\circ} \mathrm{C}$. The ion current curves where the change of signal was detected are shown in Fig. S29, S31 and S33 (ESI $\dagger$ ).

IL-1 starts decomposing at $268^{\circ} \mathrm{C}$ and complete decomposition occurs at $400{ }^{\circ} \mathrm{C}$ suggesting that only gaseous products are formed. Importantly, the $T_{\mathrm{dec}}$ value of IL-1 is higher than those 
Table 1 Physical properties of ILs

\begin{tabular}{|c|c|c|c|c|c|c|c|c|}
\hline IL & $T_{\mathrm{g}}^{a},{ }^{\circ} \mathrm{C}$ & $T_{\mathrm{dec}}{ }^{b},{ }^{\circ} \mathrm{C}$ & $\mu^{c}, \mathrm{cP}$ & $\rho^{d}, \mathrm{~g} \mathrm{~cm}^{-3}$ & $\kappa^{e}, \mathrm{mS} \mathrm{cm}^{-1}$ & Cathodic $\operatorname{limit}^{f}, \mathrm{~V}$ vs. $\mathrm{Fc} / \mathrm{Fc}^{+}$ & Anodic $\operatorname{limit}^{f}, \mathrm{~V} v s . \mathrm{Fc} / \mathrm{Fc}^{+}$ & $\mathrm{ECW}^{g}, \mathrm{~V}$ \\
\hline IL-2 & $-39.0 \pm 0.3$ & 219 & $376 \pm 20$ & $1.325 \pm 0.001$ & $1.180 \pm 0.008$ & -1.64 & 0.61 & 2.25 \\
\hline IL-3 & $-55.4 \pm 0.2$ & 234 & $414 \pm 20$ & $1.181 \pm 0.001$ & $0.731 \pm 0.110$ & -1.3 & 1.42 & 2.72 \\
\hline
\end{tabular}

${ }^{a}$ Glass transition temperatures determined by DSC. ${ }^{b}$ Onset of decomposition. ${ }^{c}$ Dynamic (shear) viscosity measured at $25{ }^{\circ} \mathrm{C}$. ${ }^{d}$ Measured at $25{ }^{\circ} \mathrm{C}$ in triplicate. ${ }^{e}$ Measured at $25{ }^{\circ} \mathrm{C} .{ }^{f}$ Cathodic and anodic limits were determined from LSV (scan rate $1 \mathrm{mV} \mathrm{s}{ }^{-1}$ ) using a glassy carbon working electrode, a Pt counter electrode and an $\mathrm{Ag} / \mathrm{AgNO}_{3} / \mathrm{Bu}_{4} \mathrm{~N}^{+} \mathrm{H}_{2} \mathrm{PO}_{4}{ }^{-}$reference electrode (Fig. 3f) applying a current density cutoff at $j=20 \mu \mathrm{A} \mathrm{cm}{ }^{-2} \cdot{ }^{g}$ Electrochemical window $(\mathrm{ECW})=$ anodic limit - cathodic limit.

for some of the known imidazolium ILs with organic anions. ${ }^{27,28}$ The decomposition of the 4,5-dicyano-1,2,3-triazol-2-ide anion involves the formation of $\mathrm{C}_{2} \mathrm{~N}_{2}{ }^{\bullet+}(m / z 52), \mathrm{N}_{2}{ }^{++}(m / z 28), \mathrm{CN}^{+}$ $(m / z 26)$ and $\mathrm{CH}^{+}(m / z$ 13) species (Fig. S29, ESI $\dagger)$. The decomposition of the 3-butyl-1,2-dimethyl-1 $H$-imidazol-3-ium cation probably involves the elimination of the $n$-butyl radical and its subsequent fragmentation along with dehydration as supported by a series of charged species with $m / z 54,53,52,51,50\left(\mathrm{C}_{4}\right.$ fragments: $\mathrm{C}_{4} \mathrm{H}_{6}{ }^{++}$, $\left.\mathrm{C}_{4} \mathrm{H}_{5}{ }^{+}, \mathrm{C}_{4} \mathrm{H}_{4}{ }^{+}, \mathrm{C}_{4} \mathrm{H}_{3}{ }^{+}, \mathrm{C}_{4} \mathrm{H}_{2}{ }^{++}\right), 44,43,42,41,40,39\left(\mathrm{C}_{3}\right.$ fragments: $\left.\mathrm{C}_{3} \mathrm{H}_{8}{ }^{++}, \mathrm{C}_{3} \mathrm{H}_{7}{ }^{+}, \mathrm{C}_{3} \mathrm{H}_{6}{ }^{\bullet+}, \mathrm{C}_{3} \mathrm{H}_{5}^{+}, \mathrm{C}_{3} \mathrm{H}_{4}{ }^{\bullet+}, \mathrm{C}_{3} \mathrm{H}_{3}{ }^{+}\right)$and 30, 29, 28, 27, $26\left(\mathrm{C}_{2}\right.$ fragments $\left.\mathrm{C}_{2} \mathrm{H}_{6}{ }^{\bullet+}, \mathrm{C}_{2} \mathrm{H}_{5}{ }^{+}, \mathrm{C}_{2} \mathrm{H}_{4}{ }^{+}, \mathrm{C}_{2} \mathrm{H}_{3}{ }^{+}, \mathrm{C}_{2} \mathrm{H}_{2}{ }^{\bullet+}\right)$. The charged species with $m / z 68$ and 66 that could be assigned to the products of imidazole ring decomposition were also detected. The proposed mechanism of IL-1 thermal decomposition is schematically depicted in Fig. S30 (ESI†).

IL-2 has the onset of decomposition at $219^{\circ} \mathrm{C}$. It loses $60 \%$ of initial mass at $350{ }^{\circ} \mathrm{C}$. The decomposition of IL-2 in the first step could involve the transfer of a methyl cation from the cation to the anion leading to the formation of $4 \mathrm{H}-1,2,4$-triazol4-amine and 2-methyl-2H-1,2,3-triazole-4,5-dicarbonitrile (Fig. S32, ESI $\dagger)$. The latter is decomposed to $\mathrm{C}_{2} \mathrm{~N}_{2}{ }^{\bullet+}(m / z 52), \mathrm{C}_{2} \mathrm{~N}^{+}(m / z 38)$ and methanediazonium $\left(\mathrm{CH}_{3} \mathrm{~N}_{2}{ }^{+}, \mathrm{m} / z\right.$ 43) as initial fragments. $\mathrm{CH}_{3} \mathrm{~N}_{2}{ }^{+}$, upon subsequent fragmentation, gives rise to other species, such as $\mathrm{CH}_{2} \mathrm{~N}_{2}{ }^{\bullet+}(m / z 42), \mathrm{CH}_{2} \mathrm{~N}_{2}{ }^{\bullet+}(m / z 40)$, diazene $\left(\mathrm{N}_{2} \mathrm{H}_{2}{ }^{\bullet}, m / z\right.$ 30), $\mathrm{CH}_{3} \mathrm{~N}^{+}$(m/z 29), etc. (Fig. S31, ESI $\dagger$ ). The decomposition of $4 H-1,2,4$-triazol-4-amine, in turn, involves the evolution of nitrogen $\left(\mathrm{N}_{2}{ }^{\bullet+}, \mathrm{m} / z 28\right)$, ammonia $\left(\mathrm{NH}_{3}{ }^{{ }^{+}}\right.$, $m / z$ 17) and $\mathrm{C}_{2} \mathrm{HN}^{\bullet+}(\mathrm{m} / \mathrm{z} 39)$ (Fig. S31, ESI $\left.\dagger\right)$. The latter could give $\mathrm{HCN}^{\bullet+}(m / z 27)$ and $\mathrm{CN}^{+}(m / z 26)$ charged species, while the liberation of ammonia is supported by the presence of $\mathbf{N}^{+}(m / z 14), \mathrm{NH}^{\bullet+}(m / z 15), \mathrm{NH}_{2}{ }^{+}(m / z 16)$ and $\mathrm{NH}_{4}{ }^{+}(m / z 18)$.

Interestingly, the introduction of a nitro group into the triazole ring did not destabilize the respective anion significantly. IL-3 starts decomposing at $234{ }^{\circ} \mathrm{C}$ and loses $90 \%$ of the initial mass at $300{ }^{\circ} \mathrm{C}$. The $N$-butylimidazolium cation follows the decomposition pattern described for IL-1 above and includes the elimination of butyl radical that upon further decay gives a set of characteristic $\mathrm{C}_{4}, \mathrm{C}_{3}$ and $\mathrm{C}_{2}$ fragments (Fig. S34, ESI $\dagger$ ). On the other hand, anion decomposition could involve elimination of $\mathrm{NO}^{+}(\mathrm{m} / \mathrm{z} 30)$ accompanied by $\mathrm{OH}^{+}$ion $(\mathrm{m} / \mathrm{z} 17), \mathrm{N}_{2}{ }^{\bullet+}(\mathrm{m} / \mathrm{z} 28)$ and presumably $\mathrm{HC}_{2} \mathrm{~N}^{\bullet+}(m / z$ 39) (Fig. S33, ESI $\dagger)$. The latter, however, overlaps with the signal of $\mathrm{C}_{3} \mathrm{H}_{3}{ }^{+}$.

In order to estimate long term thermal stability of ILs, we performed isothermal TGA at $120{ }^{\circ} \mathrm{C}$ for $10 \mathrm{~h}$. This temperature exceeds the typical operational temperature for the most common processes and could serve on a first approximation as a parameter describing the longstanding stability of an $\mathrm{IL}^{29}$ Under the applied conditions, IL-1 has lost $0.5 \%$ of the initial mass, while IL-2 and IL-3 lost about 1.3\% (Fig. 3c). The densities of the synthesized ILs are in the range of $1.107-1.325 \mathrm{~g} \mathrm{~cm}^{-3}$ (Table 1). Typically the presence of water affects the densities of ILs within the range of $1-2 \% .^{30}$

The novel ILs behave as Newtonian fluids in the range of shear rates $500-3000 \mathrm{~s}^{-1}$ (Fig. 3d). IL-1 has the lowest dynamic viscosity of $85 \mathrm{cP}$ at $25{ }^{\circ} \mathrm{C}$, among the ILs presented in the current work (Table 1). IL-2 and IL-3 have viscosities of 376 and $414 \mathrm{cP}$, respectively. The viscosities of the ILs gradually decrease with temperature and reach a plateau at $70-80{ }^{\circ} \mathrm{C}$ (Fig. 3e). The viscosity of the ILs also depends on the water content and for $\left[\mathrm{C}_{4} \operatorname{mim}\right]\left[\mathrm{Tf}_{2} \mathrm{~N}\right]$, for example, it is $33 \%$ lower when the water content increases from 10 to $10480 \mathrm{ppm} .{ }^{31}$ Nevertheless, IL-1 possesses a lower viscosity compared, for example, to $\left[\mathrm{C}_{4} \mathrm{mim}\right]\left[\mathrm{PF}_{6}\right]$ $\left(397 \mathrm{cP}, w_{\mathrm{w}}=0.0117,25{ }^{\circ} \mathrm{C}\right)$ and $\left[\mathrm{C}_{6} \mathrm{mim}\right]\left[\mathrm{PF}_{6}\right](452 \mathrm{cP}$, $w_{\mathrm{w}}=0.008837,25^{\circ} \mathrm{C}$ ) having nearly the same water content. ${ }^{32}$

The conductivities of ILs were determined using electrochemical impedance spectroscopy (EIS) (Table 1). Widegren and Magee have shown that the conductivity of ILs depends on the water content and for dry $\left[\mathrm{C}_{6} \operatorname{mim}\right]\left[\mathrm{Tf}_{2} \mathrm{~N}\right]\left(w_{\mathrm{w}}=10^{-5}\right)$, for example, it is $2.18 \mathrm{mS} \mathrm{cm}^{-1}$, which is $30 \%$ lower compared to that of the same IL, but measured under wet conditions $\left(3.06 \mathrm{mS} \mathrm{cm}{ }^{-1}, w_{\mathrm{w}}=0.00898,25^{\circ} \mathrm{C}\right) .{ }^{33}$ The conductivities of the newly synthesized ILs are comparable, for example, to those of aforementioned $\left[\mathrm{C}_{6} \mathrm{mim}\right]\left[\mathrm{Tf}_{2} \mathrm{~N}\right]$ and $\left[\mathrm{C}_{4} \mathrm{mim}\right]\left[\mathrm{Tf}_{2} \mathrm{~N}\right]\left(5.42 \mathrm{mS} \mathrm{cm}^{-1}\right.$, $\left.w_{\mathrm{w}}=0.00885,25{ }^{\circ} \mathrm{C}\right) .{ }^{34}$ In addition, the conductivities of the ILs reported here are higher than those of $\left[\mathrm{aP}_{4443}\right][\mathrm{Ala}]\left(0.244 \mathrm{mS} \mathrm{cm}^{-1}\right.$, $\left.w_{\mathrm{w}}=0.0169\right),\left[\mathrm{aP}_{4443}\right][\mathrm{Val}]\left(0.116 \mathrm{mS} \mathrm{cm}^{-1}, w_{\mathrm{w}}=0.0157\right)$ and $\left[\mathrm{aP}_{4443}\right][\mathrm{Leu}]\left(0.114 \mathrm{mS} \mathrm{cm}^{-1}, w_{\mathrm{w}}=0.0151\right)$ measured at $25{ }^{\circ} \mathrm{C}$ and having higher water contents. ${ }^{35}$

In order to overcome the influence of viscosity, especially for IL-3, and to achieve equilibrium conditions, linear sweep voltammetry (LSV) measurements were performed at a low scan rate of $1 \mathrm{mV} \mathrm{s}^{-1}$ (Fig. 3f). ${ }^{36}$ The electrochemical window (ECW) of the IL naturally depends on the current density cutoff used for calculations. ${ }^{37}$ We applied a very low current density cutoff, $j=20 \mu \mathrm{A} \mathrm{cm}^{-2}$, which is considerably lower than that generally used in the literature, in order to avoid overestimation of the ECW (Table 1). Thus, IL-1 has the widest electrochemical window (ECW) among the studied compounds, $3.02 \mathrm{~V}$. On the other hand, IL-2 has the highest stability on the cathodic side, $-1.64 \mathrm{~V}$. The ECW of IL-3 is $2.72 \mathrm{~V}$, and the anodic limit, $1.42 \mathrm{~V}$, is higher than those in the cases of IL-1 and IL-2. This implies that 5-nitro-1,2,4-triazol-1-ide is more stable against oxidation 
than 4,5-dicyanotriazole-1,2,3-2-ide. In comparison with other ILs, the ECWs of the electrolytes presented here are wider despite using much lower current density cutoff values. To support this the following ILs having similar water contents could be mentioned: $\left[\mathrm{C}_{4} \mathrm{mpyrr}\right]\left[\mathrm{Tf}_{2} \mathrm{~N}\right]\left(2.0 \mathrm{~V}, w_{\mathrm{w}}=0.011407\right.$, $\left.j=1 \mathrm{~mA} \mathrm{~cm}^{-2}\right),\left[\mathrm{C}_{4} \mathrm{mim}\right][\mathrm{I}]\left(2.0 \mathrm{~V}, w_{\mathrm{w}}=0.011349, j=1 \mathrm{~mA} \mathrm{~cm}^{-2}\right)$ and $\left[\mathrm{N}_{6,2,2,2}\right]\left[\mathrm{Tf}_{2} \mathrm{~N}\right]\left(2.2 \mathrm{~V}, w_{\mathrm{w}}=0.0082, j=1 \mathrm{~mA} \mathrm{~cm}{ }^{-2}\right)$, all measured at $+25{ }^{\circ} \mathrm{C}$ using a $\mathrm{Pt}$ microdisc as the working electrode and a Pt wire as the quasi-reference electrode. ${ }^{37}$

Three new "fully organic" ILs, which are built only from C, $\mathrm{N}, \mathrm{O}$, and $\mathrm{H}$ elements and comprise heterocycles as cation and anion building blocks, have been synthesized. Their physical properties were measured and compared to known ILs taking into account the water contents. The obtained results suggest that the electrolytes reported here have higher conductivity, wider ECW and lower viscosities than those of some of the known ILs. And these are in addition to good thermal stability. All these features make the ILs reported here suitable for energy storage applications. Moreover, due to the basic properties of the anions and the presence of a large number of nitrogen atoms, these ILs could be used as a reaction medium to accomplish desired chemical transformations, for example, $\mathrm{CO}_{2}$ reduction.

The work was supported by Deutsche Forschungsgemeinschaft (grant number DFG-An 156 13-1). We thank Antje Völkel, Ursula Lubahn and Sylvia Pirok for TGA-MS, DSC and elemental analysis, respectively. Open Access funding provided by the Max Planck Society.

\section{Conflicts of interest}

There are no conflicts to declare.

\section{References}

1 S. V. Malhotra, Ionic Liquids in Organic Synthesis, American Chemical Society, Washington, DC, 2007.

2 A. A. J. Torriero, Electrochemistry in Ionic Liquids, Springer International Publishing, 2015.

3 Y. Zhang, X. Chen, J. Lan, J. You and L. Chen, Chem. Biol. Drug Des., 2009, 74, 282-288.

4 N. D. Vos, C. Maton and C. V. Stevens, ChemElectroChem, 2014, 1, 1258-1270.

5 P. C. Howlett, E. I. Izgorodina, M. Forsyth and D. R. MacFarlane, Z. Phys. Chem., 2006, 220, 1483-1498.

6 V. R. Koch, A. Dominey, C. Nanlundiah and M. J. Ondrechen, J. Electrochem. Soc., 1996, 143, 798-803.

7 M. G. Freire, C. M. S. S. Neves, I. M. Marrucho, J. A. P. Coutinho and A. M. Fernandes, J. Phys. Chem. A, 2010, 114, 3744-3749.

8 J. M. Aizpurua, R. M. Fratila, Z. Monasterio, N. Pérez-Esnaola, E. Andreieff, A. Irastorza and M. Sagartzazu-Aizpurua, New J. Chem., 2014, 38, 474-480.

9 H. F. D. Almeida, H. Passos, J. A. Lopes-da-Silva, A. M. Fernandes, M. G. Freire and J. A. P. Coutinho, J. Chem. Eng. Data, 2012, 57, 3005-3013.
10 C. Yue, D. Fang, L. Liu and T.-F. Yi, J. Mol. Liq., 2011, 163, 99-121. 11 Y. Jeong and J.-S. Ryu, J. Org. Chem., 2010, 75, 4183-4191.

12 Y. Jeong, D.-Y. Kim, Y. Choi and J.-S. Ryu, Org. Biomol. Chem., 2011, 9, 374-378.

13 M.-C. Tseng, H.-T. Cheng, M.-J. Shen and Y.-H. Chu, Org. Lett., 2011, 13, 4434-4437.

14 S. Sanghi, E. Willett, C. Versek, M. Tuominen and E. B. Coughlin, RSC Adv., 2012, 2, 848-853.

15 S. Kitaoka, K. Nobuoka, N. Yoshiiwa, T. Harran and Y. Ishikawa, Chem. Lett., 2010, 39, 1142-1143.

16 A. D. McNaugh, A. Wilkinson, M. Nic, J. Jirat, B. Kosata and A. Jenkins, IUPAC. Compendium of Chemical Terminology XML on-line corrected version: http://goldbook.iupac.org (2006-), Blackwell Scientific Publications, Oxford, 2nd (the "Gold Book") edn, 1997.

17 R. L. Thompson, W. Shi, E. Albenze, V. A. Kusuma, D. Hopkinson, K. Damodaran, A. S. Lee, J. R. Kitchin, D. R. Luebke and H. Nulwala, RSC Adv., 2014, 4, 12748-12755.

18 N. Hollingsworth, S. F. R. Taylor, M. T. Galante, J. Jacquemin, C. Longo, K. B. Holt, N. H. d. Leeuwad and C. Hardacre, Faraday Discuss., 2015, 183, 389-400.

19 S. F. R. Taylor, C. McCrellis, C. McStay, J. Jacquemin, C. Hardacre, M. Mercy, R. G. Bell and N. H. d. Leeuw, J. Solution Chem., 2015, 44, 511-527.

20 J. J. Fillion, H. Xia, M. A. Desilva, M. Quiroz-Guzman and J. F. Brennecke, J. Chem. Eng. Data, 2016, 61, 2897-2914.

21 H. Xue, Y. Gao, B. Twamley and J. n. M. Shreeve, Inorg. Chem., 2005, 44, 5068-5072.

22 M.-J. Crawford, K. Karaghiosoff, T. M. Klapötke and F. A. Martin, Inorg. Chem., 2009, 48, 1731-1743.

23 R. Petersen, J. F. Jensen and T. E. Nielsen, Org. Prep. Proced. Int., 2014, 46, 267-271.

24 G. Drake, T. Hawkins, K. Tollison, L. Hall, A. Vij and S. Sobaski, in Ionic Liquids IIIB: Fundamentals, Progress, Challenges, and Opportunities, ed. R. D. Rogers and K. R. Seddon, American Chemical Society, Washington, DC, 2005, vol. 902, ch. 20, pp. 259-302.

25 M. Holzweber, W. E. S. Unger and V.-D. Hodoroaba, Anal. Chem., 2016, 88, 6967-6970.

26 A. R. Santos, R. K. Blundell and P. Licence, Phys. Chem. Chem. Phys., 2015, 17, 11839-11847.

27 M. T. Clough, K. Geyer, P. A. Hunt, J. Mertes and T. Welton, Phys. Chem. Chem. Phys., 2013, 15, 20480-20495.

28 M. Babucci, A. Akçay, V. Balci and A. Uzun, Langmuir, 2015, 31, 9163-9176.

29 A. I. Siriwardana, in Electrochemistry in Ionic Liquids, ed. A. A. J. Torriero, Springer International Publishing, 2015, vol. 2, Applications, ch. 20, pp. 563-603.

30 J. Jacquemin, P. Husson, A. A. H. Padua and V. Majer, Green Chem., 2006, 8, 172-180.

31 J. A. Widegren, A. Laesecke and J. W. Magee, Chem. Commun., 2005, 1610-1612.

32 J. G. Huddleston, A. E. Visser, W. M. Reichert, H. D. Willauer, G. A. Broker and R. D. Rogers, Green Chem., 2001, 3, 156-164.

33 J. A. Widegren and J. W. Magee, J. Chem. Eng. Data, 2007, 52, 2331-2338.

34 J. A. Widegren, E. M. Saurer, K. N. Marsh and J. W. Magee, J. Chem. Thermodyn., 2005, 37, 569-575.

35 Z. Wang, L. Fu, H. Xu, Y. Shang, L. Zhang and J. Zhang, J. Chem. Eng. Data, 2012, 57, 1057-1063.

36 X. Lu, G. Burrell, F. Separovic and C. Zhao, J. Phys. Chem. B, 2012, 116, 9160-9170.

37 A. M. O'Mahony, D. S. Silvester, L. Aldous, C. Hardacre and R. G. Compton, J. Chem. Eng. Data, 2008, 53, 2884-2891. 